\title{
The Effects of Oral Supplementation of Bitter Melon (Momordica charantia L.) Leaves Extract on the VEGF Serum Level in Diabetic Foot Ulcers: Randomized Controlled Trial
}

\author{
Fahrun Nur Rosyid $^{1 *}$, Tomy Adi Prasetyo ${ }^{2}$, Muhtadi $^{3}$, K Heri Nugroho HS $^{4}$ \\ $\left\{\right.$ fnr100@ums.ac.id $\left.{ }^{1}\right\}$ \\ Department of Medical Surgical Nursing, School of Nursing, Universitas Muhammadiyah Surakarta, \\ Surakarta, Indonesia ${ }^{1,2}$ \\ Profesor, Faculty of Pharmacy, Universitas Muhammadiyah Surakarta, Surakarta, Indonesia ${ }^{3}$ \\ Division of Endocrinology and Metabolism, Department of Internal Medicine, Faculty of Medicine, \\ Diponegoro University, Semarang, Indonesia ${ }^{4}$
}

\begin{abstract}
The purpose of this study is to determine the effect of oral Bitter Melon (Momordica charantia L.) leaves extract on the serum VEGF level in diabetic foot ulcers. The trial was randomized, double-blinded, and placebo-controlled. Thirty diabetic foot ulcer (DFU) patients with a PEDIS score of 1-8 who met the criteria were divided into two groups: The treatment group received the bitter melon leaves extract orally at a dose of 6 $\mathrm{g} /$ day, while the control group received a placebo. The intervention lasted four weeks, and baseline and end-of-treatment VEGF serum levels were determined. The paired t-test and independent t-test were used to analyze the data. After four weeks of treatment, the baseline VEGF serum level in the treatment group decreases from 431.5248 .5 to $236.9158 \mathrm{pg} / \mathrm{ml}$ (the decline begins at $194.5197 .9 \mathrm{pg} / \mathrm{ml}$ ). Meanwhile, in the control group, the concentration decreases from 382.4351,4 to $191.6121 .9 \mathrm{pg} / \mathrm{ml}$ (the concentration decreases to $190.8324 .9 \mathrm{pg} / \mathrm{ml})$. The effect of oral supplementation with Bitter Melon leaves extract on VEFG serum levels was found to be insignificant $(\mathrm{p}=0.39)$. Oral bitter melon leaf extract supplementation was not shown to increase VEFG serum levels in DFU patients.
\end{abstract}

Keywords: Bitter melon, momordica charantia L., VEGF, diabetes mellitus, diabetic foot ulcer

\section{Introduction}

Increased prevalence of diabetes mellitus (DM) may result in an increase in the incidence of DFU [1]. Diabetes mellitus biochemically is able to cause complications in organ systems irreversibly in both the parenchyma structure and peripheral structure. In DM, DFU and amputation are the most common complications [2]. DFU refers to the main cause for nontraumatic foot amputations, thus, significantly causing disability, morbidity and mortality [3-4]. Additionally, it imposes significant physical, physiological, and financial burdens on patients and the general public. At the moment, it is estimated that DFU accounts for $24.4 \%$ of total health care expenditures in DM [5].

Diabetic foot ulcers increase the apoptosis of fibroblast cells, decreases fibroblast cell proliferation and prolong the inflammatory reactions, as seen from the presence of large 
numbers of granulocytes neutrophils in the wound [6], the increase of local and systemic TNF$\alpha$ in the type-2 DM patients [7]. At a normal level, fibroblast cells are unable to increase the VEGF production in responding to the hypoxic condition and this then makes the VEGF level low. This results in the accumulation of advanced glycosylation end products (AGEs) in cells exposed to chronic hyperglycemia and oxidative damage as a result of excessive mitochondrial oxidative stressor production. Both cause a permanent cell damage even though the environment has had normoglycemia [8]. VEGF is a growth factor that is involved in the neovascularization of wound healing [9].

Charantin contained in bitter melon is as a PR angiogenesis through the increase of Mitogen Activated Protein Kinase (MAPK) that will activate Extracellular Signal Regulated Kinases (ERK), later on causing the cell proliferation, migration and endhotel tube formation [10]. By increasing protease activity and endothelial cell migration, saponin bitter melon can stimulate angiogenesis [11]. The activation of these endothelial cells can increase VEGF secretion as an important mediator in blood vessel formation [12].

Infection control, inflammation repair, connective tissue matrix regeneration, angiogenesis/vasculogenesis, wound constriction, and re-epithelialization are all required for wound healing [13]. DFU management is costly, and even some of these medications have a variety of side effects. Additionally, DFU patients must first normalize their blood glucose levels, which will almost certainly prolong wound healing time. These facts then justify the use of bitter melon leaves as a supplement to enhance treatment effectiveness. Additionally, it can serve as a medium for promoting health and disease treatment. The purpose of this study is to determine the effect of oral bitter melon (Momordica charantia L.) extract supplementation on the serum VEGF level in DFU patients.

\section{Method}

\subsection{Making the bitter melon leaves extract}

Bitter melons (Momordica charantia L.) were collected in Boyolali, Central Java, Indonesia, on agricultural land. We chose only the best leaves (characterized by flat, fresh green leaves). Following that, they were washed and dried in a drying cupboard. The dried bitter melon leaves are ground into a coarse powder and macerated in 50 percent ethanol for 3-5 days until completely submerged. Following maceration, the results were filtered using a vacuum burgher and then evaporated using an evaporator until thick. The slightly thick extract was again evaporated on the water bath to thicken it until the water content was less than $20 \%$. The thick extracts obtained were homogenized by adding amprotab/corn starch in a 1:2 ratio. Then, the extract mixture was dried in an oven at the temperature of $40^{\circ} \mathrm{C}$ and smoothed with a blender. The fine powder was placed into the capsules made at Clinical Pharmacy Laboratory of UMS.

\subsection{Clinical trial}

The Dr. Moewardi General Hospital in Surakarta, Indonesia, conducted this study using a randomized, double-blind, placebo-controlled design. The Health Research Ethics Committee of General Hospital Dr. Moewardi/School of Medicine, Universitas Sebelas Maret, Surakarta, Indonesia approved this research protocol. 


\subsection{Patients}

Patients who met the criteria were those with a PEDIS score of 1-8, aged 30 - 65 years, with a hemoglobin level of $>10 \mathrm{~g} / \mathrm{dl}$, an IMT level of $18.5-22.9$, an albumin level of $>3 \mathrm{~g} / \mathrm{dl}$, and a Brachial Ankle Index (ABI) of > $0.6-1.3$, with a duration of diabetes of $0-15$ years, willing to participate in research and sign an informed consent form. Meanwhile, the excluded patients included those scheduled for minor amputations (Below or Above Knee), chronic hypoxia, sepsis, aged 30 years or older than 65 years, experiencing stress, obesity, consuming alcohol, smoking, as well as those with comorbidities (cardiovascular disease, lung disease, and immunology), receiving steroid therapy or chemotherapy, or who dropped out. The flow chart in Figure 1 illustrates the recruitment and follow-up of patients.

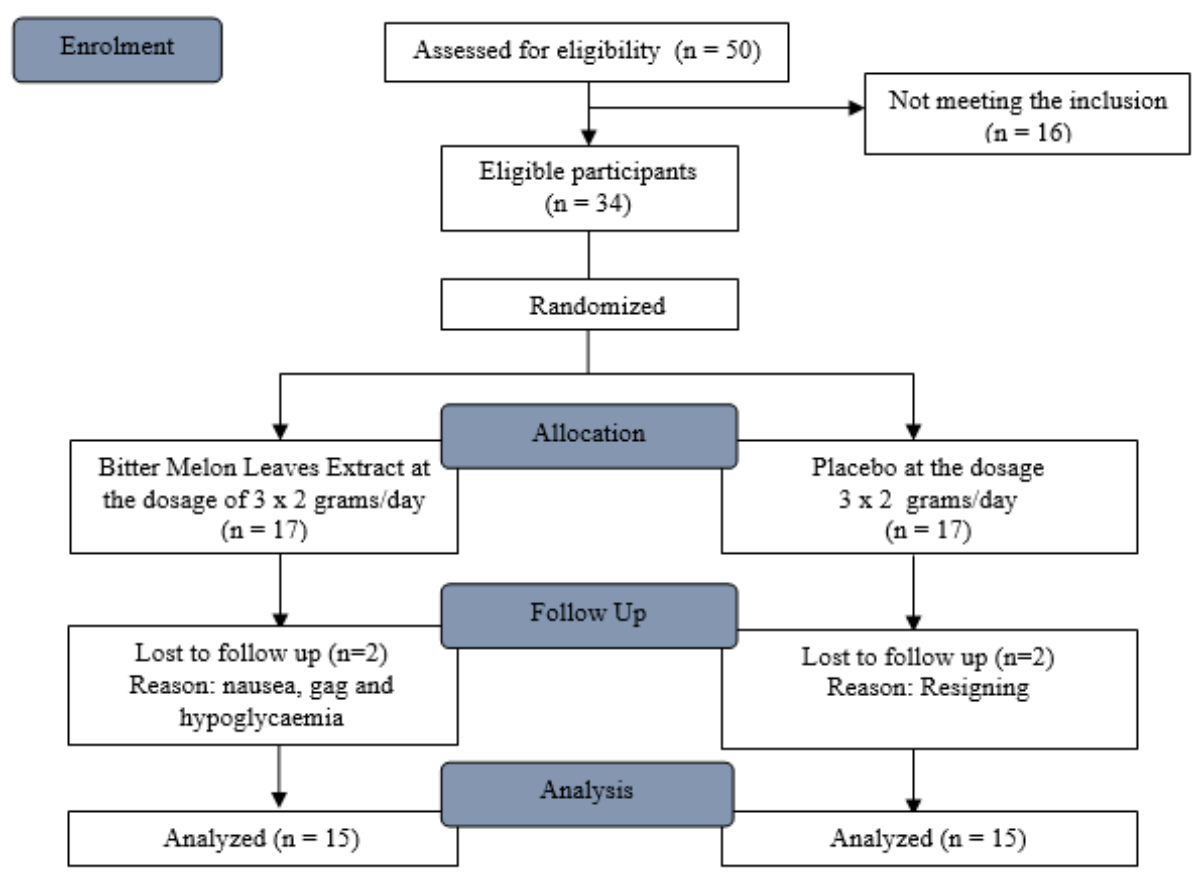

Fig.1. Flow of participants through the trial.

\subsection{Study procedure}

Additionally, eligible patients were randomly assigned to one of two groups: the treatment group or the control group. The treatment group received $3 \times 2$ grams of Bitter Melon leaves extract orally for 4 weeks, while the control group received a placebo. At the conclusion of this study, medication adherence was determined by counting the number of medications taken and interviewing patients in each control group. 


\subsection{Outcome measurement}

The primary efficacy result is a change in VEGF serum levels measured using ELISA method. Serum VEGF levels were determined at baseline and at the end of week 4 in both groups.

\subsection{Statistical analysis}

The research findings are summarized as follows: the number of patients (n), the mean, and the standard deviation. SPSS was used to analyze the data; a value of P 0.05 was considered statistically significant. If the variable under study was not normally distributed, the nonparametric statistic method was used. The mean difference analysis was used to compare the results of the VEFG level measurement to those of the paired t-test and independent t-test.

\section{Results and discussions}

\subsection{Results}

This study enrolled thirty patients with DFU. All DFU patients were randomly assigned to one of two groups: the treatment group $(n=15)$ received Bitter Melon leaves extract orally at a dose of $6 \mathrm{~g} /$ day, while the control group $(n=15)$ received a placebo. The baseline characteristics of the two groups revealed no differences show at Table 1.

Table1. The baseline characteristics of patients

\begin{tabular}{llll}
\hline Variables & Treatment Group & Control Group & p-value \\
\hline Age (year) & $55 \pm 7.3$ & $53.1 \pm 8.6$ & 0.30 \\
\hline Sex & & & 0.56 \\
Male (\%) & $9(60)$ & $11(73.3)$ & \\
Female (\%) & $6(40)$ & $4(26,7)$ & \\
\hline Education & & & 0.54 \\
Primary School (\%) & $1(6.7)$ & $1(6.7)$ & \\
Middle School (\%) & $8(53.3)$ & $10(66.7)$ & \\
High School (\%) & $4(26.7)$ & $2(13.3)$ & \\
Higher Education (\%) & $2(13.3)$ & $2(13.3)$ & \\
\hline Occupation & & & 0.31 \\
Housewife (\%) & $6(40)$ & $9(60)$ & \\
Entrepreneur (\%) & $8(53.3)$ & $4(26.6)$ & \\
Civil Servant (\%) & 0 & $1(6.7)$ & \\
Retirement (\%) & $1(6,7)$ & $1(6.7)$ & \\
\hline Body Weight (kg) & $56.9 \pm 8.9$ & $56 \pm 7.5$ & 0.45 \\
\hline Body Mass Index (kg/m ${ }^{2}$ ) & $21.6 \pm 1.3$ & $21,7 \pm 1.3$ & 0.64 \\
\hline Length in suffering from DM (in year) & $8.5 \pm 5.9$ & $8.47 \pm 6.6$ & 0.38 \\
\hline Length in suffering from ulcer (in week) & $23.1 \pm 34.8$ & $24.40 \pm 33$ & 0.69 \\
\hline PEDIS score & $4.5 \pm 1.4$ & $5.3 \pm 2.1$ & 0.23 \\
\hline Antidiabetic Medicine (OAD) & & & 1.00 \\
Yes (\%) & $15(100)$ & $15(100)$ & \\
No (\%) & 0 & 0 & \\
\hline
\end{tabular}




\begin{tabular}{llll}
\hline Ankle Brachial Index (ABI) & $0.9 \pm 0.1$ & $1 \pm 0.1$ & 0.22 \\
\hline
\end{tabular}

There was no difference in any of the baseline variables (age, gender, education level, occupation, body weight, body mass index (BMI), duration of diabetes mellitus (DM), duration of ulcer, PEDIS score, antidiabetic medication, and ankle brachial index (ABI)) between the treatment and control groups. After four weeks of treatment, VEGF serum levels decreased significantly from baseline (194.5197.9 $\mathrm{pg} / \mathrm{ml}, \mathrm{p}=0.002$ and $190.8324 .9 \mathrm{pg} / \mathrm{ml}, \mathrm{p}=0.04)$; however, there was no effect on VEGF serum levels $(\mathrm{p}=0.39)$.

\subsection{Discussion}

VEGF is a mediator in angiogenesis [14-15]. The process of active angiogenesis occurs on the third day after the injury occurs [16]. As a result, the level of VEGF should have increased on that day. VEGF promotes blood vessel growth (sprouting) and a strong angiogenic response, as well as the expression of serine proteases urokinase- and tissue-type plasminogen activators (PA) and PA inhibitor 1 (PAI-1) in microvascular endothelial cells, which helps maintain the protolithic process in balance. It increases the expression of metalloproteinase interstitial collagenase. The simultaneous influence on collagenase and plasminogen activator by VEGF will determine a productive environment for the migration and growth of endothelial cells. This environment is a critical component of the cellular process chain because it acts as a link between cellular invasion and tissue remodeling, as VEGF's permanent proangiogenic activity does. VEGF is also referred to as a vasculature permeability factor because it promotes vascular leakage. Increased microvascular permeability is a critical stage of tumor and wound angiogenesis. VEGF's primary function during the angiogenesis process is to promote plasma protein leakage, resulting in the formation of extravascular fibrin gel, a substrate for endothelial and tumor cell penetration and growth [17]. Table 2 show that The effects of Bitter Melon Leaves Extract on the Level of VEGF Serum.

Table 2. The effects of Bitter Melon Leaves Extract on the Level of VEGF Serum

\begin{tabular}{lllll}
\hline Variables & Week 1 & $\Delta$ on Week 4 & $p{\text { within } \text { group }^{\mathrm{a}}}$ & $p$ inter-group $^{\mathrm{b}}$ \\
\hline Level of VEGF $(\mathrm{pg} / \mathrm{ml})$ & & & & \\
Treatment Group & $431,5 \pm 248,5$ & $-194,5 \pm 197,9$ & 0,002 & 0,39 \\
Control Group & $382,4 \pm 351,4$ & $-190,8 \pm 324,9$ & 0,04 & \\
\hline
\end{tabular}

Data are stated with the mean \pm SD.

The modified values of level of VEGF Serum showed significantly different for time or treatment effects (Independent $\mathrm{t}$ Test) at $p<0,05$.

${ }^{a} p<0,05$ At the same time period, there is a significant difference in the change values between the treatment and control groups (Paired t-test)

${ }^{\mathrm{b}} p<0,05$ After four weeks, there is a significant difference in the change values (Independent $t$ test)

The results of this study showed no difference at the VEGF serum level in both treatment group and control group. The baseline of initial serum VEGF levels in the treatment group and control groups were found above the normal rate. Then, after giving the bitter melon and placebo extracts there was a decrease, but still within normal limits. Baba et al. (2001) examining the VEGF levels in DM patients with the level of $\mathrm{HbA1c}>7.5 \%$ and on average suffering from DM for 13 years showed the baseline of VEGF level of 33-37pg/ml [18]. Dantz, et al (2002) 
conducted a study on the effect of hypoglycemia on VEGF, while the results showed that normal adult male VEGF levels before treatment were $86.1 \pm 13.4 \mathrm{pg} / \mathrm{ml}$ [19]. Other studies related to VEGF in malignant disease have shown the normal VEGF level at $<300 \mathrm{pg} / \mathrm{ml}$ (in the range of $8.11 \pm 1.60 \mathrm{pg} / \mathrm{ml}$ to $294.20 \pm 23.40 \mathrm{pg} / \mathrm{ml}$ ) with the difference based upon age and sex [20-21] . It has been known that VEGF level increases within 24 hours after the injury and reaches a peak on the third and seventh day and dramatically decreases [22]. The results of this study were inconsistent with the studies reporting the pro-angiogenic effects of bitter melon supplementation by stimulating proliferation, migration and tube formation in healing ulcers due to diabetes [10] and by stimulating the growth factors, such as insulin [23].

The conditions that regulate VEGF gene expression are as follows: (1) hypoxia, oxygen pressure plays a critical role in the regulation of VEGF gene expression both in vitro and in vivo. Rapid and reversible induction of VEGF mRNA expression occurs in response to hypoxia (pO2), as well as ischemia caused by arterial occlusion. An increase in VEGF mRNA levels suggests that VEGF can promote spontaneous revascularization after ischemia. [17]. Impaired systemic VEGF levels have been reported in a variety of pathological conditions such as tumor growth, coronary artery disease and chronic hypoxic diseases. This observation is thought to be related to oxygen regulation [24]. For respiratory diseases manifested by chronic hypoxia, VEGF regulation is still conflicting. Respiratory disease such as idiopathic pulmonary fibrosis, VEGF levels are decreased compared to controls in healthy people, whereas in smokers and chronic obstructive pulmonary disease (COPD) are increasing [24]. However, all of these data can be confused by the presence of comorbid known to affect VEGF such as insulin resistance [25]; (2) Cytokines, or specific cytokines or growth factors, induce the expression of VEGF mRNA and/or the release of VEGF protein. TNF- is the most potent activator of VEGF mRNA expression, whereas IL-1, TGF-1, and Interleukin-6 have a lesser effect. (3) Differentiation and transformation; differentiation and transformation play a critical role in the regulation of VEGF gene expression. VEGF mRNA expression is increased during the transition of 3T3 preadipocytes to adipocytes or during $\mathrm{C} 2 \mathrm{C} 12$ myogenic differentiation. In contrast, when pheochromocytoma cells differentiate into nonmalignant neuron-like cells, VEGF gene expression is decreased or suppressed [17].

\section{Conclusion}

The oral supplementation of bitter melon extract can reduce serum VEGF levels in the DFU patients. This study suggests to do an examination for the tissue oxygen pressure and number of adipocyte cells to observe its effects on serum VEGF levels.

\section{Acknowledgments}

The study was funded by Universitas Muhammadiyah Surakarta pursuant to Decree No. 78.1/A.3-III/LPPM/II/2019. We would like to express our gratitude to Dr. Moewardi, the Hospital Director in Surakarta, Central Java, Indonesia, and to all participants in this study.

Ethics approval. The Commission of Health Research Ethics Dr. Moewardi/Medical Faculty of UNS, Surakarta, Indonesia approved the protocol (Number: 542/IV/HREK/2019), which complies with the Helsinki Declaration. 
Conflicts of interest. All authors report no conflict of interest

\section{References}

[1] K. Bakker and N. C. Schaper, "The development of global consensus guidelines on the management and prevention of the diabetic foot 2011," Diabetes. Metab. Res. Rev., vol. 28, pp. 116-118, Feb. 2012, doi: 10.1002/dmrr.2254.

[2] J. Berlanga-Acosta, G. S. Schultz, E. López-Mola, G. Guillen-Nieto, M. García-Siverio, and L. Herrera-Martínez, "Glucose toxic effects on granulation tissue productive cells: The diabetics' impaired healing,” Biomed Res. Int., vol. 2013, 2013, doi: 10.1155/2013/256043.

[3] H. M. Maier, J. Z. Ilich, J.-S. Kim, C. W. Levenson, B. H. Arjmandi, and M. T. Spicer, "Dietary advanced glycation end-products exacerbate oxidative stress in patients with diabetic foot ulcers," J. Diabetes Res. Clin. Metab., vol. 3, no. 1, p. 2, 2014, doi: 10.7243/2050-0866-3-2.

[4] S. Morbach et al., "Long-term prognosis of diabetic foot patients and their limbs: Amputation and death over the course of a decade," Diabetes Care, vol. 35, no. 10, pp. 2021-2027, 2012, doi: $10.2337 / \mathrm{dc} 12-0200$.

[5] M. R. Sargen, O. Hoffstad, and D. J. Margolis, "Geographic variation in Medicare spending and mortality for diabetic patients with foot ulcers and amputations," J. Diabetes Complications, vol. 27, no. 2, pp. 128-133, 2013, doi: 10.1016/j.jdiacomp.2012.09.003.

[6] K. B. Hobizal and D. K. Wukich, "Diabetic foot infections: Current concept review," Diabet. Foot Ankle, vol. 3, pp. 1-8, 2012, doi: 10.3402/dfa.v3i0.18409.

[7] J. J. Swaroop, D. Rajarajeswari, and J. N. Naidu, "Association of TNF- $\alpha$ with insulin resistance in type 2 diabetes mellitus," Indian J. Med. Res., vol. 135, no. 1, pp. 127-130, 2012, doi: 10.4103/09715916.93435.

[8] K. Al-rubeaan, M. Al Derwish, S. Ouizi, and A. M. Youssef, "Diabetic Foot Complications and Their Risk Factors from a Large Retrospective Cohort Study," vol. 53, no. Cvd, pp. 1-17, 2015, doi: 10.1371/journal.pone.0124446.

[9] H. Brem et al., "Mechanism of Sustained Release of Vascular Endothelial Growth Factor in Accelerating Experimental Diabetic Healing,” J. Invest. Dermatol., vol. 129, no. 9, pp. 2275-2287, Sep. 2009, doi: 10.1038/jid.2009.26.

[10] A. Aljohi, S. Matou-Nasri, and N. Ahmed, "Antiglycation and antioxidant properties of Momordica charantia," PLoS One, vol. 11, no. 8, pp. 1-14, 2016, doi: 10.1371/journal.pone.0159985.

[11] G. Y. Lee et al., "Effects of Panax ginseng extract on human dermal fibroblast proliferation and collagen synthesis," Int. Wound J., vol. 13, pp. 42-46, 2016, doi: 10.1111/iwj.12530.

[12] D. Kent and C. Sheridan, "Choroidal neovascularization: A wound healing perspective," Mol. Vis., vol. 9, no. June, pp. 747-755, 2003.

[13] O. C. Velazquez, "Angiogenesis \& Vasculogenesis: Inducing the growth of new blood vessels and wound healing by stimulation of Bone Marrow Derived Progenitor Cell Mobilization and Homing," Bone, vol. 23, no. 1, pp. 1-7, 2011, doi: 10.1161/CIRCULATIONAHA.110.956839.

[14] T. Velnar, T. Bailey, and V. Smrkolj, "The wound healing process: An overview of the cellular and molecular mechanisms," J. Int. Med. Res., vol. 37, no. 5, pp. 1528-1542, 2009, doi: $10.1177 / 147323000903700531$.

[15] G. I. I. Broughton, J. E. Janis, and C. E. Attinger, "Wound Healing: An Overview," Plast. Reconstr. Surg., vol. 117, no. 7S, 2006, [Online]. Available: https://journals.lww.com/plasreconsurg/Fulltext/2006/06001/Wound_Healing_An_Overview.29.a spx.

[16] J. L. Monaco and W. T. Lawrence, “Acute wound healing: An overview,” Clin. Plast. Surg., vol. 30, no. 1, pp. 1-12, Jan. 2003, doi: 10.1016/S0094-1298(02)00070-6.

[17] N. Ferrara and T. Davis-Smyth, "The Biology of Vascular Endothelial Growth Factor," Endocr. Rev., vol. 18, no. 1, pp. 4-25, Feb. 1997, doi: 10.1210/edrv.18.1.0287. 
[18] T. Baba, K. Shimada, S. Neugebauer, D. Yamada, S. Hashimoto, and T. Watanabe, "The Oral Insulin Sensitizer, Thiazolidinedione, Increases Plasma Vascular Endothelial Growth Factor in Type 2 Diabetic Patients," Diabetes Care, vol. 24, no. 5, pp. 953 LP - 954, May 2001, doi: 10.2337/diacare.24.5.953.

[19] D. Dantz et al., "Vascular endothelial growth factor: A novel endocrine defensive response to hypoglycemia," J. Clin. Endocrinol. Metab., vol. 87, no. 2, pp. 835-840, 2002, doi: 10.1210/jcem.87.2.8215.

[20] Y. Yamamoto et al., "Concentrations of vascular endothelial growth factor in the sera of normal controls and cancer patients," Clin. Cancer Res., vol. 2, no. 5, pp. 821-826, 1996.

[21] J. Yang, W. Li, X. He, G. Zhang, L. Yue, and Y. Chai, "VEGF overexpression is a valuable prognostic factor for non-Hodgkin's lymphoma evidence from a systemic meta-analysis," Dis. Markers, vol. 2015, 2015, doi: 10.1155/2015/786790.

[22] S. Frank, G. Hubner, G. Breier, M. T. Longaker, D. G. Greenhalgh, and S. Werner, "Regulation of vascular endothelial growth factor expression in cultured keratinocytes. Implications for normal and impaired wound healing," Journal of Biological Chemistry, vol. 270, no. 21. pp. 12607-12613, 1995, doi: $10.1074 /$ jbc.270.21.12607.

[23] R. Singh, I. Garcia-Gomez, K. P. Gudehithlu, and A. K. Singh, "Bitter Melon Extract Promotes Granulation Tissue Growth and Angiogenesis in the Diabetic Wound," Adv. Skin Wound Care, vol. 30, no. 1, 2017, [Online]. Available: https://journals.1ww.com/aswcjournal/Fulltext/2017/01000/Bitter_Melon_Extract_Promotes_Granu lation_Tissue.4.aspx.

[24] S. Guo and L. A. DiPietro, "Critical review in oral biology \& medicine: Factors affecting wound healing,” J. Dent. Res., vol. 89, no. 3, pp. 219-229, 2010, doi: 10.1177/0022034509359125.

[25] J. Webster, P. Scuffham, M. Stankiewicz, and W. P. Chaboyer, "Negative pressure wound therapy for skin grafts and surgical wounds healing by primary intention," Cochrane Database Syst. Rev., no. 10, Oct. 2014, doi: 10.1002/14651858.CD009261.pub3. 